\title{
REFLEXÃO DE JOVENS PESQUISADORES SOBRE A EXPERIÊNCIA EDUCATIVA DIANTE DO CONTEXTO PANDÊMICO DA COVID-19
}

\author{
A. M. B. do N. TAVARES ${ }^{1}$, B. D. da SILVA ${ }^{2}$ \\ Instituto Federal de Educação, Ciência e Tecnologia do Rio Grande do Norte ${ }^{1}$, Universidade do Minho ${ }^{2}$ \\ ORCID ID: https://orcid.org/0000-0001-6857-7947 ${ }^{1}$ \\ andrezza.tavares@ifrn.edu.br ${ }^{1}$
}

Submetido 22/10/2020 - Aceito 29/10/2020

DOI: $10.15628 /$ holos.2020.11427

\begin{abstract}
RESUMO
É inegável o momento de crise que a humanidade passa a atravessar a partir da disseminação do novo Coronavírus. O contexto pandêmico impactou profundamente a dinâmica do mundo do trabalho, provocando alterações no funcionamento das organizações que assumiram o formato remoto, destacadamente as instituições de educação escolar. O presente estudo aborda uma experiência de educação online integradora desenvolvida junto ao projeto de extensão "Diálogos sobre Capital Cultural e Práxis do IFRN - Edição Internacional". O objetivo é analisar o conteúdo de entrevistas realizadas por jovens pesquisadores do programa de pós-graduação em Ciências da Educação da Universidade do Minho
\end{abstract}

(Portugal), publicadas no Jornal Potiguar Notícias, com o propósito de refletir sobre a experiência educativa nestes tempos de pandemia. O recorte temporal das entrevistas compreendeu os meses de junho e julho do ano 2020. O procedimento metodológico utilizado baseou-se na análise temática, com apoio do software NVivo12, na qual foram inferidos tópicos que se desmembraram em temas e subtemas sobre os assuntos levantados nas vinte e três entrevistas. Apesar dos inúmeros desafios enfrentados, os resultados apontam que o contexto de educação remota mobilizou professores, estudantes e famílias para o complexo e criativo exercício da educação mediada pelas tecnologias de informação e comunicação.

PALAVRAS-CHAVE: Jovens pesquisadores, Educação Remota, Educação a Distância, Mídia online, COVID-19.

\section{REFLECTIONS OF YOUNG RESEARCHERS ABOUT THE EDUCATIONAL EXPERIENCE IN THE PANDEMIC CONTEXT OF COVID-19}

\begin{abstract}
The crisis humanity faces with the spreading of the new Coronavirus is undeniable. The pandemic context has profoundly impacted the dynamics of the world of work, causing changes in the functioning of the organizations that adopted a remote model, outstandingly, the institutions of school education. The present study approaches an integrative online educational experience developed along with the extension project "Dialogues about Cultural Capital and Praxis of FIRN - International Edition". The purpose is to analyze the content of interviews made by young researchers of the post graduation program of Educational Sciences of the Minho University (Portugal), published in Jornal Potiguar
\end{abstract}

Notícias, aiming to reflect about the educational experience in pandemic times. The time frame of the interviews comprised the months of June and July of 2020. The methodological procedure used was based on thematic analysis, with aid of the software NVivo12, in which it were inferred topics that were broken down into themes and subthemes about the subjects raised on twenty-three interviews. Despite of countless challenges faced, the results point out that the remote education context has mobilized teachers, students, and families for the complex and creative exercise of education mediated by information and communication technologies.

KEYWORDS: Young researchers, Remote education, Distance education, Online media, COVID-19. 


\section{INTRODUÇÃO}

É inegável que a pandemia motivada pelo novo Coronavírus, deflagrada desde dezembro de 2019, localizada inicialmente na cidade de Wuhan na China e, em seguida, propagada por todo o planeta, representa um contexto de grave crise sanitária, social, econômica e política imposta para a humanidade. A nova forma de infecção altamente contagiosa, rapidamente afetou milhões de vítimas em todo o mundo e, lamentavelmente, decorrido quase um ano de seu início não se tem uma vacina específica para a sua mitigação e combate.

A pandemia sobrecarregou os sistemas de saúde e trouxe prejuízos impensáveis à economia, em todos os países. Países têm fechado as suas fronteiras, governos e prefeituras têm proibido espaços de circulação de pessoas. No mundo todo foram cancelados jogos, congressos, eventos, acessos internacionais, entre outras importantes agendas de impacto social e cultural. Sem dúvida, a partir da COVID-19 a humanidade passou a viver uma das estações mais doídas de sua contemporaneidade, enfrentando muitos desafios.

No mundo, a constatação da letalidade do Coronavírus é agravada em função do histórico cenário de desigualdade social e de polarização político-económica desenhados internacionalmente. A organização mundial de saúde, ao tratar do ciclo de contaminação em diferentes regiões do planeta, ressalta que, apesar da contaminação atingir inicialmente o seu platô nas cidades mais populosas dos países, é uma consequência certa que a doença ainda permanece por longo tempo em seus territórios passando a se propagar entre as cidades mais provincianas.

Em tempo de profundo desenvolvimento científico e tecnológico desenvolvido por sucessivas revoluções industriais, enquanto a corrida pela produção da vacina não se consolida a humanidade se apoia em rústicos procedimentos para a mitigação da COVID-19 tais como: o isolamento social, a higiene das mãos, o uso de máscaras e a contenção de contatos físicos. Outro aspecto extremamente valioso para o enfrentamento do cenário pandêmico é o alargamento da imersão humana nos espaços virtuais proporcionados pelas tecnologias digitais e pela internet e nesse aspecto ressaltamos a importância das experiências de educação online que vêm se desdobrando em todo o planeta.

O objetivo deste artigo é analisar o conteúdo de vinte e três (23) entrevistas, por meio de abordagem qualitativa do grounded theory, com apoio do software NVivo12, realizadas por jovens pesquisadores do programa de pós-graduação em Ciências da Educação da Universidade do Minho (Portugal), vivendo em diferentes países e continentes, com pesquisas em curso ou recémconcluídas, com o propósito de refletir sobre a experiência educativa nestes tempos de pandemia, tomando como ponto de partida os projetos ou experiências educativas em que estão envolvidos, a fim de ilustrar ideias que possam colaborar com as pessoas neste momento de isolamento social. O recorte temporal da pesquisa compreendeu os meses de junho e julho do ano 2020 quando o projeto de extensão promoveu articulação pluri-institucional entre o Instituto Federal de Educação, Ciência e Tecnologia do Rio Grande do Norte (IFRN), a Universidade do Minho e o Jornal Potiguar Notícias. 
A publicação, em periódico científico, dos resultados percebidos com as entrevistas dos jovens pesquisadores compreende uma das ações perseguidas pelo projeto pluri-institucional de extensão "Diálogos sobre Capital Cultural e Práxis do IFRN - Edição Internacional" na medida em que tem produzido dados a partir de produção de notícias no jornalismo sobre os impactos que o tempo pandêmico tem reverberado no contexto de trabalho no na educação.

Elaborou-se o artigo em três seções. Na primeira, fazem-se umas breves notas sobre o projeto de extensão "Diálogos sobre Capital Cultural e Práxis do IFRN - Edição Internacional", perspectivado na educação online dialógica; na segunda, referem-se os caminhos metodológicos da pesquisa, e na terceira apresentam-se os resultados da análise de conteúdo das entrevistas.

\section{NOTAS SOBRE O PROJETO DE EXTENSÃO PERSPECTIVADO NA EDUCAÇÃO ONLINE DIALÓGICA}

O Projeto "Diálogos sobre Capital Cultural e Práxis do Instituto Federal do Rio Grande do Norte (IFRN) - Edição Internacional” é uma iniciativa vinculada à Diretoria de Extensão (DIREX) do campus IFRN Natal Central e ao Programa de Pós-Graduação Acadêmica em Educação Profissional (PPGEP) do IFRN. A experiência de extensão inspirada na educação online articula práxis do campo epistêmico da Educação a partir de atividades de ensino, pesquisa, extensão, inovação e internacionalização com o campo da comunicação social a partir da dinâmica de produções jornalísticas por meio de diversos canais de diálogo social como: portal de jornal eletrônico, TV web, TV aberta, rádio e redes sociais.

A ideia do projeto é alargar a comunicação sobre o campo da educação por meio de notícias nos veículos de comunicação que privilegiem os conceitos e acontecimentos impulsionadores de desenvolvimento humano, beneficiando a comunidade escolar e a sociedade ampliada na medida em que acessam processos comunicativos colaboradores da consciência crítica e cidadã.

As ações principais vislumbradas pelo projeto são: 1) realizar oficina com estudantes sobre educação e jornalismo enquanto campos complementares de formação de sujeitos críticos e reflexivos; 2) analisar informações e conteúdo, edição e gravação áudio-visual sobre cidadania e práxis educativa; 3) apurar e publicar informações e conteúdo por meio do jornal eletrônico Potiguar Notícias sobre cidadania e sobre as práxis; 4) realizar oficina com estudantes sobre os conceitos cunhados por Bourdieu (1989): capital cultural, capital intelectual, capital simbólico, campo e habitus; bem como, sobre conceitos cunhados por Freire (2005) como pedagogia libertadora, pedagogia da autonomia e dialogicidade.

No início do mês de março do ano 2020, quando o coronavírus obrigou todas as pessoas a tomarem medidas de confinamento social (todo o mundo em suas casas), o projeto de extensão online assumiu uma configuração pluri-institucional por meio de atividade online integradora que mobilizou a produção de notícias no jornalismo sobre o cenário pandêmico. $O$ primeiro texto produzido neste contexto foi publicado no Jornal Potiguar em 21 de março, com o título "PANDEMIA: contexto de transformação de comportamento" (Santos, 2020). Neste artigo não se vai atender a toda a publicação efetuada, mas apenas, como já pontuamos, às entrevistas realizadas 
com jovens pesquisadores do Programa de Pós-Graduação em Ciências da Educação da Universidade do Minho (Portugal), realizadas e publicadas nos meses de junho e julho do ano de 2020.

As narrativas apresentadas pelas fontes entrevistadas expressaram como a educação remota se desenvolveu em diferentes países e continentes. Esse movimento de produção e de publicação das entrevistas internacionais sobre a educação em tempo pandêmico se tornou possível graças ao trabalho integrador realizado pelas instituições Instituto Federal de Educação, Ciência e Tecnologia do Rio Grande do Norte (IFRN), o Jornal Potiguar Notícias e a Universidade do Minho (Portugal).

O convite aos jovens pesquisadores da UMinho se dá em virtude do convênio, e respectivos termos aditivos, de cooperação acadêmica que esta instituição tem com o IFRN, celebrado em 2012 e renovado em 2016, estando em vigor na atualidade. O protocolo de cooperação, na sua cáusula primeira, especifica que o mesmo "tem como objetivo desenvolver a cooperação interuniversitária nos campos da ciência e da pesquisa, da arte e da cultura, assim como em todas as iniciativas de mútuo interesse das partes". Estabelecido contato com o responsável da UMinho no campo da educação, entendeu-se que era de mútuo interesse lançar o desafio aos jovens pesquisadores em Ciências da Educação, a fim de, tomando como ponto de partida os seus projetos de pesquisa, contribuírem com reflexões que pudessem ajudar as pessoas nestes momentos de isolamento social, sobretudo a professores, alunos e famílias, face ao encerramento das escolas e paragem das atividades letivas presenciais, com subsequente transição para processos de ensino e de aprendizagem realizados a distância com recurso das tecnologias de informação e comunicação.

As instituições de educação que dialogam com a sociedade sobre as suas ideias e as suas práxis, na medida em que promovem alianças entre os campos da Educação e da Comunicação Social, alargam os espaços críticos e reflexivos de interatividade e de desenvolvimento comunitário. A atividade de educação com jornalismo potencializa oportunidades de ativismo filosófico e pedagógico, inclusive, por meio de denúncias de cenários alienadores e excludentes. O projeto de extensão "Diálogos sobre Capital Cultural e Práxis do IFRN - Edição Internacional” deseja contribuir com profissionais da educação e da comunicação social progressistas engajados com a reverberação de ideias sobre educação, cidadania e humanização.

\section{CAMINHOS METODOLÓGICOS DA PESQUISA}

A iniciativa partiu de um convite, em forma de desafio, dirigido aos estudantes de pósdoutoramento, doutoramento e mestrado, em Ciências da Educação, na especialidade de Tecnologia Educativa, orientados pelo professor responsável do Instituto de Educação pelo convênio UMinho / IFRN. Dizia esse e-mail enviado em 31 de maio de 2020, a 12 estudantes: 


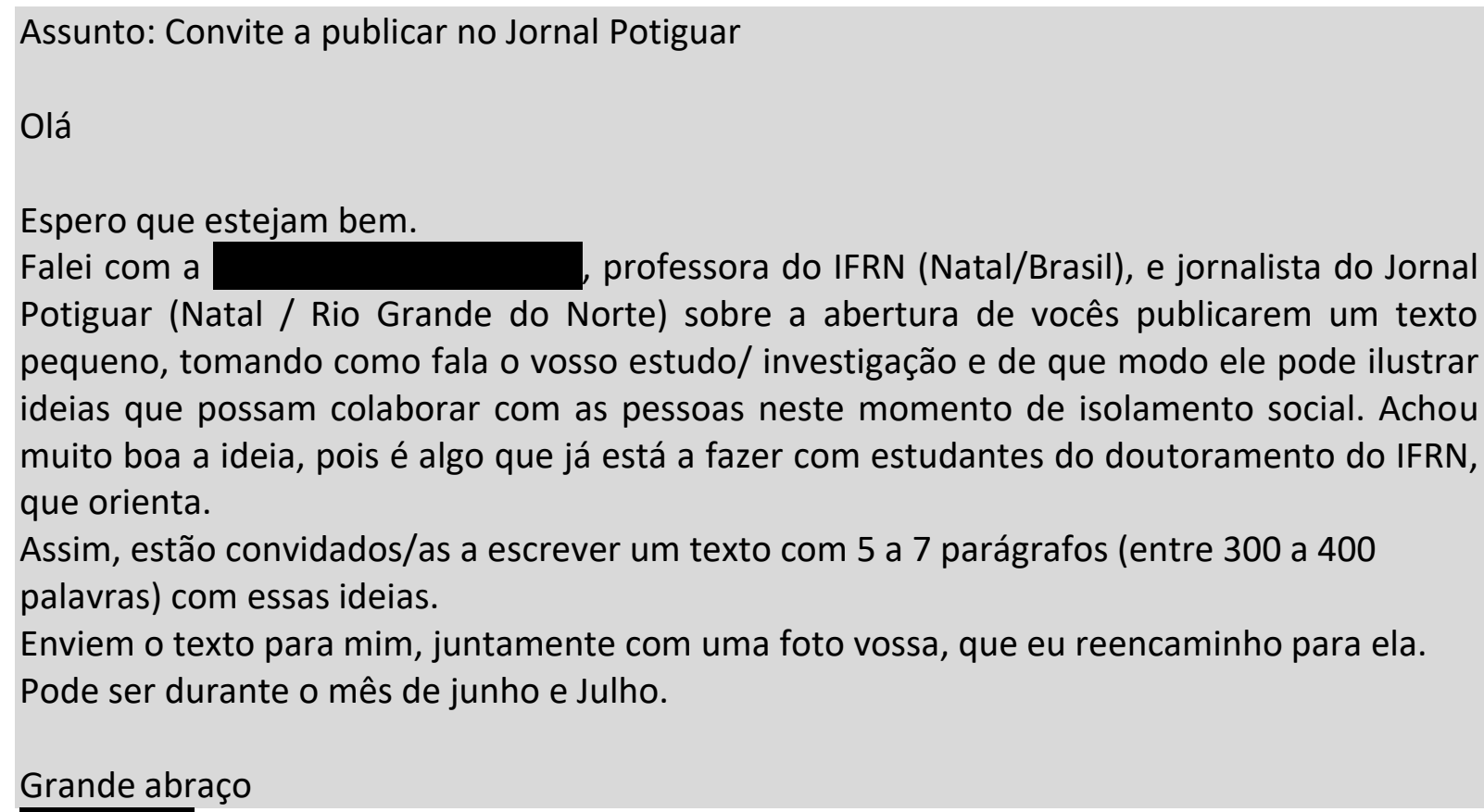

Figura 1: E-mail enviado dia 31 de maio de 2020, a 12 estudantes.

Havia uma pergunta de partida para esse texto: de que modo o estudo/investigação que estão a desenvolver pode ilustrar ideias que possam colaborar com as pessoas neste momento de isolamento social?

Logo após o envio do convite, alguns estudantes, para além de aceitarem o desafio, sugeriram que o mesmo fosse alargado aos colegas que nos dois últimos períodos letivos tinham frequentado as especialidades de "Tecnologia Educativa" e de "Desenvolvimento Curricular" do Programa de Doutoramento (têm várias unidades curriculares em comum no programa doutoral), pois estavam com a pesquisa de doutoramento em curso, bem como a outros estudantes que tivessem concluído seus estudos recentemente, de modo particular os estudantes oriundos dos países africanos de expressão portuguesa. Deste modo, diziam nas sugestões, se o desafio fosse aceito ter-se-ia uma ideia como nesses países se estava a reagir à pandemia em termos educativos. Houve acolhimento destas sugestões de alargamento de participantes e, à medida que os textos iam sendo publicados no Jornal Potiguar Notícias e se ia fazendo sua divulgação nas redes facebook e whashapp, com diversas reações, mais estudantes de outras especialidades do Programa Doutoral se mostraram interessados em publicar suas experiências educativas durante a pandemia. Deste modo, ao longo deste periodo (1 e-mail convite enviado em 31 de maio) enviou-se convite para 38 estudantes, com projetos em curso e também para alguns que tinham concluído seus estudos recentemente, tendo 23 aderido à iniciativa. A tabela 1 dá conta do vínculo à área de estudos, sendo natural que "Tecnologia Educativa" e "Desenvolvimento Curricular" sejam as mais representadas pois foram os estudantes destas áreas a quem foi feito o convite diretamente. 
Tabela 1: Área de estudos pós-graduados em Ciências da Educação no IE/UMinho dos participantes na iniciativa do Jornal Potiguar Notícias

\begin{tabular}{c|c|c|c|c|c|c}
\hline $\begin{array}{c}\text { Área de estudos pós- } \\
\text { graduados em Ciências da } \\
\text { Educação no IE/UMinho }\end{array}$ & $\begin{array}{c}\text { Pos- } \\
\text { Dout. }\end{array}$ & Doutor. & Mest. & $\begin{array}{c}\text { Em } \\
\text { curso }\end{array}$ & Concl. & Total \\
\hline Tecnologia Educativa & 1 & 9 & 4 & 9 & 5 & 14 \\
\hline Desenvolvimento Curricular & & 6 & & 5 & 1 & 6 \\
\hline Psicologia da Educação & & 1 & & 1 & & 1 \\
\hline Supervisão Pedagógica & & 1 & & 1 & & 1 \\
\hline $\begin{array}{c}\text { Organização e Administração } \\
\text { Escolar }\end{array}$ & 1 & & 1 & & 1 \\
\hline Total & $\mathbf{1}$ & $\mathbf{1 8}$ & $\mathbf{4}$ & $\mathbf{1 7}$ & $\mathbf{6}$ & $\mathbf{2 3}$ \\
\hline
\end{tabular}

Fonte: Próprios autores (2020)

Estes pesquisadores são provenientes de sete países (de quatro continentes) e na altura do convite encontravam-se nas localidades de origem, com exceção de dois estudantes do Brasil que se encontravam em Portugal (Braga), em trabalho de campo pois as pesquisas têm como contexto de aplicação situações educativas no respetivo país de origem. O mapa na Figura 2 mostra as localidades de origem dos pesquisadores. Assim, da Europa há seis pesquisadores, cinco de Portugal (localidades de Barcelos, Braga, Guimarães e Santa Maria da Feira). Da América do Sul, há onze pesquisadores, sendo dez do Brasil, o país mais representado (localidades de Recife/Pernambuco, São Luís/Maranhão, Bragança/Pará, Manaus/Amazonas, Nova Iguaçu/Rio de Janeiro, Fortaleza/Ceará, Rio Branco/Acre e Santa Maria/Rio Grande do Sul) e um do Equador (Portoviejo). De África, há seis pesquisadores, sendo dois de Cabo Verde (localidades da Praia/Santiago), dois de Angola (localidades de Lubango e Cunene) e dois de Moçambique (localidades de Maputo e Tete). Da Ásia, há um pesquisador, em Timor (Dili) que, embora seja português, se encontra na Universidade Nacional Timor Lorosa'e, onde coordena um Projeto.

Esta diversidade geográfica, por continentes e países, se revelou enriquecedora para esta pesquisa na medida em que nos deu uma dimensão mais ampla, do impacto da pandemia na educação a nível internacional. Acresce, ainda, que todos os pesquisadores exercem atividade profissional no setor educativo, a maioria é professor, em vários níveis de ensino (há professores desde o nível fundamental ao superior), pelo que são conhecedores, em primeira mão, das vivências que atravessam o sistema educacional, podendo, assim, apresentar reflexões mais ricas, pois aliam a experiência profissional a pesquisa em educação advinda dos projetos em que estão envolvidos. 


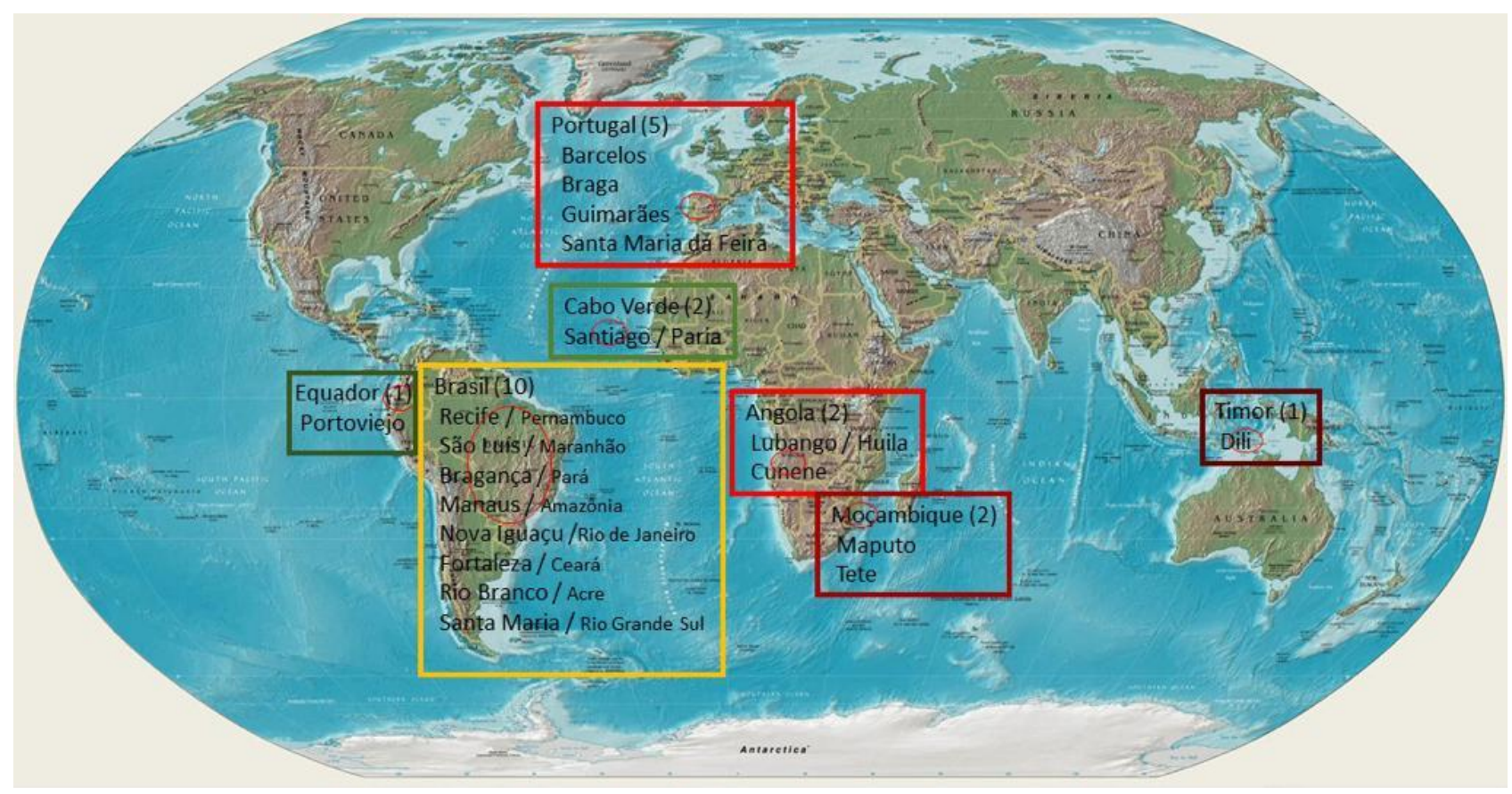

Figura 2: Mapa com a origem dos jovens pesquisadores.

Fonte: Próprios autores (2020)

Já nos referimos à questão de partida para idealizar as ideias do texto, muito abertas, sem qualquer restrinção, ou seja, para além da questão de partida não havia outras, deixando total liberdade ao autor. Apenas se referia que o texto devia ser breve, entre 300 a 400 palavras, não devendo passar de sete parágrafos e, como o objetivo era para ser publicado no jornalismo, a linguagem devia ser bem acessível aos leitores.

Era, então, a partir desse texto que se levantavam as questões da entrevista, em princípio uma para cada parágrafo do texto, sendo o texto transformado em entrevista num processo interativo que se estabelecia entre autores (pesquisadores) e entrevistadores. Então, já na forma de entrevista, o texto/entrevista retornava ao autor para em diálogo com todos os envolvidos de proceder a algum aprimoramento, se necessário, para finalmente se dar a publicação no Jornal Potiguar Notícias.

A opção pela entrevista deve-se ao fato de ser um dos formatos nobres do gênero informativo no jornalismo e por permitir, também, de forma mais transparente possível, sinalizar a intervenção, em seguida ao professor do IE/UMinho e da jornalista do Jornal Potiguar Notícias, também professora do IFRN, onde é coordenadora do Projeto pluri-institucional "Diálogos sobre Capital Cultural e Práxis do Instituto Federal do Rio Grande do Norte (IFRN) - Edição Internacional". O texto entrevista ficaria vinculado a este Projeto de Extensão do IFRN, contribuindo-se, deste modo, para reforçar com esta nova vertente a parceria que existe entre estas duas instituições.

A análise das entrevistas baseou-se nas técnicas sugeridas para dados qualitativos pela análise temática (Braun \& Clarke, 2006, 2013), com apoio do software NVivo12. Trata-se de um método qualitativo que se configura como uma técnica flexível que fornece uma análise rica e detalhada de dados. Na sua aplicação adotam-se os seguintes conceitos centrais: tema, subtema, 
código, organizador central e mapa temático. Um tema permite captar padrões comuns do conjunto dos dados que são importantes para as questões da pesquisa, a qual, no presente estudo, tem a ver com refletir sobre a experiência educativa nestes tempos de pandemia, tomando como ponto de partida os projetos ou experiências educativas em que os jovens investigadores estão envolvidos.

Para se compreender o grande quadro desta questão de partida, como sugerido na análise para dados qualitativos pela grounded theory (Strauss \& Corbin, 1990), é importante seguir os outros conceitos da análise temática, como detectar os subtemas (elementos específicos de um tema), os códigos (unidades menores da análise, que identificam uma característica específica de um segmento de dados) e, sobretudo, o organizador central, a ideia principal em torno da qual se agrupam os dados e se estabelecem as relações entre os temas. Para se alcançar este desiderato, há fases a seguir que orientam o trabalho de análise, tais como: familiarização com os dados; codificação; busca de temas; revisão dos temas; definição dos temas; e produção do relatório. A familiarização com os dados, que se caracterizou pelo processo da leitura e releitura das entrevistas, é a base para a percepção dos temas abordados. Na busca de temas inicia-se o processo de relacionamento dos códigos com os temas e os subtemas, e aqui as representações gráficas são um apoio valioso. Aliás, em todo este processo de análise, o apoio do software NVivo12 foi fundamental, sobretudo na relação dos temas com os subtemas, ao criar, graficamente, uma teia de assuntos associados aos temas.

A última fase da análise temática é a produção do relatório, que iremos apresentar a seguir recorrendo à evocação das palavras mais frequentes usadas nas entrevistas, as quais permitiram esclarecer os temas encontrados, que, por sua vez, argumentam em relação à questão que presidiu ao lançamento deste desafio aos jovens investigadores: refletir sobre a experiência educativa nestes tempos de pandemia provocada pelo coronavírus.

\section{APRESENTAÇÃO E INTERPRETAÇÃO DE RESULTADOS QUALITATIVOS DAS ENTREVISTAS}

As nuvens de palavras espelham a frequências de palavras e permitem-nos identificar as ideias gerais expressas pelos respondentes. Verificamos que as palavras de mais elevada ocorrência (frequência) são aquelas cujo significado remetem para Educação (freq. 82), palavra que aumenta a ocorrência com a junção de palavras com sentido semelhante e que o software não o fez, como Educativo/a (freq. 28), Educacional/ais (freq, 26), o que dá um total de 136 ocorrências para esta palavra; Ensino (freq. 112); Digital (freq. 77); Professor (freq. 71); Escola (freq. 68); Social (freq. 65); Aprendizagem (freq. 57); Aluno (freq. 56) e Estudante (freq. 48), palavras com sentido semelhante que dão um total de 104 ocorrências; e Pandemia (freq, 47).

A representação gráfica da nuvem, em forma de movimento, traduz a interação estabelecida em torno das palavras, cada uma das quais remetendo para um tema, o qual, por sua vez, se associa a outros subtemas. 


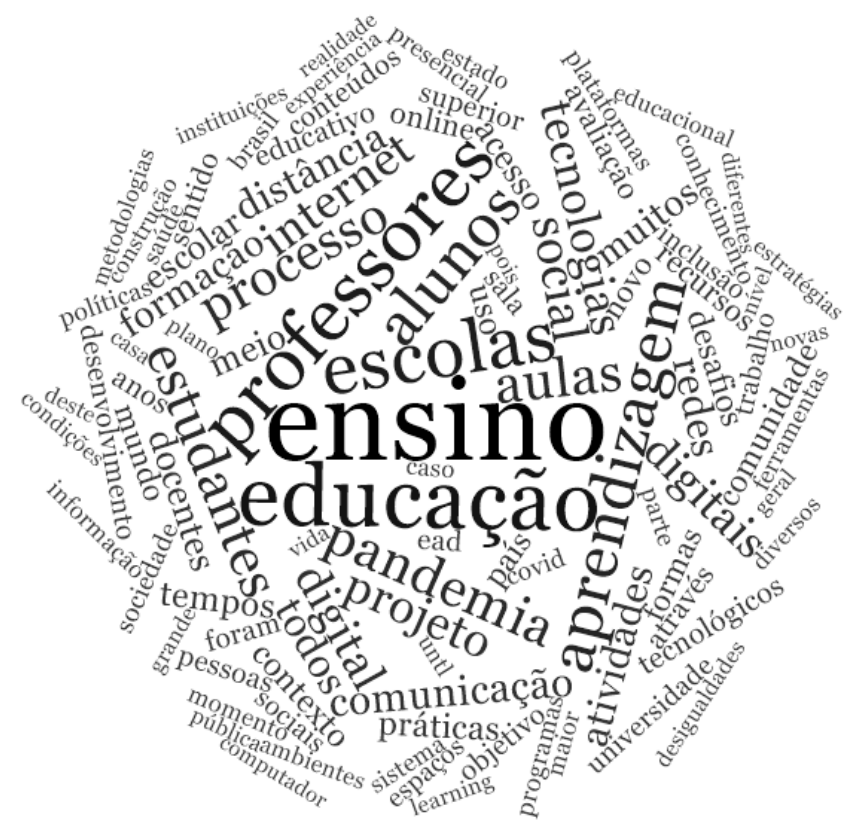

Figura 3: Representação gráfica da nuvem de palavras criada pelo software Nvivo.

A função pesquisa de texto do NVivo, em torno das palavras com mais frequência, criou uma teia de conceitos que elucidou sobre os temas abordados nas entrevistas. Estas métricas auxiliam a compreender o grande quadro, a estrutura dos subtemas associados às temáticas, análise sugerida para dados qualitativos pela grounded theory (Strauss \& Corbin, 1990). Não é possível apresentar essas teias gráficas em torno dos temas devido à grande quantidade de subtemas para que remetem, dificultando a visibilidade em formato normalizado, assim, vamos procurar traduzir por palavras essas teias.

Vamos iniciar a análise temática por PANDEMIA, muito embora não seja a palavra mais referida (freq. 47), mas é a que remete para o fato que deu origem a toda esta situação, vivida em todos os países do mundo. Este tema é abordado em todos os textos entrevistas, como seria natural. De forma geral, como as entrevistas se iniciaram em junho, os pesquisadores falam na ocorrência deste fenômeno, iniciado no início do ano de 2020, e que em março teve como consequência, perante o desconhecimento de formas de combater o vírus e a doença designada de COVID (freq. 16), a adoção de medidas como o isolamento social e o encerramento de diversas atividades como as que ocorreram nas escolas. Os textos entrevistas abordam o período temporal durante, como foram as respostas educativas nos respetivos países (palavra que ocorre 29 vezes), mas também refletem sobre o tempo pós-pandemia. O sentido geral dado a este tema pode ser exemplificado com este extrato do texto entrevista no 3:

A pandemia impôs o isolamento social, mudando radicalmente o estilo de vida das pessoas através de várias restrições que, de certa forma, podem-se repercutir no seu equilíbrio físico e psicológico, confinando-as às suas próprias ilhas [...] (porém) "se a pandemia nos isolou nas nossas próprias ilhas, as tecnologias digitas estão a combater a insularidade garantindo o vital suporte social através de uma das suas principais funções: a comunicação em rede" (Ribeirinha, 2020). 
Nos pontos seguintes veremos algumas respostas para o período durante e pós-pandemia dadas pelos pesquisadores nas entrevistas, nomeadamente nos temas Educação, Ensino, Aprendizagem, Professor, Aluno, Digital, Social e Escola.

\subsection{Educação}

O tema Educação acompanha todos os textos das entrevistas, funciona como o organizador central do conjunto dos dados, remetendo para contextos da política educativa. Assim, alguns textos abordam os Planos Nacionais da Educação e as respostas que os ministérios da educação formularam face à pandemia, temas tratados de forma mais incidente em textos sobre Cabo Verde, Equador e Timor Leste. Para Cabo Verde, o tema é abordado nos textos entrevistas no 18 (Nogueira, 2020) e sobretudo no no 22 com referências ao "Plano Nacional de resposta aos efeitos da COVID19 na Educação" (Cardoso, 2020); para o Equador, o texto no 15 toma referência o plano educacional "Vamos aprender juntos em casa" (Leal, 2020); e para Timor Leste, o texto entrevista no 19 descreve o plano de ação para o período de suspensão das atividades acadêmicas (Faria, 2020). Em todos os países, o Plano de resposta passou pelo recurso à Educação a Distância (EaD) e, em cada país, equacionaram-se "as condições e os mecanismos de implementação possíveis e o funcionamento contingencial da EaD, nos ensinos pré-escolar e escolar" (Cardoso, 2020), como é sinalizado no texto entrevista sobre a situação ocorrida em Cabo Verde. A situação relatada neste país é exemplificativa desse tipo de planos:

Uma EaD híbrida, designação que considero mais adequado à realidade vivida em Cabo Verde, foi desenvolvida e implementada, envolvendo um projeto designado de "Aprender e estudar em Casa" (...) Basicamente, o projeto constou das aulas televisivas e radiodifundidas, gravadas a partir das estruturas centrais e envolvendo os serviços da rádio educativa, professores e técnicos e equipamentos dos serviços públicos da comunicação social. O projeto EaD foi composto de um programa educativo, produção de aulas para disseminação nacional, formação de professores (exploração de recursos digitais), o acompanhamento dos alunos através de plataformas EaD envolvendo delegações, professores e pais, todos esses com responsabilidades partilhadas. (Cardoso, 2020).

Ainda a nível da política educativa há dois textos entrevistas a fazer referência ao papel dos Conselhos Municipais de Educação (CME), órgão consultivo que atua a nível do município numa ação de proximidade ao território educativo da comunidade. Um texto, o no 11, é sobre o CME do município de Nova Iguaçu (estado do Rio de Janeiro, BR) (Coelho, 2020), e outro, o no 16, é sobre um município português onde a pesquisadora aborda a articulação entre o CME e as escolas no âmbito do Projeto Educativo Municipal (Magalhães, 2020). No município português, apesar de não ter havido qualquer articulação e os projetos educativos das escolas não terem sido formalmente alterados por este tempo pandêmico, houve diversas mudanças emergentes que na opinião dos diretores das escolas inquiridos pela pesquisadora "irão manter-se, especialmente o uso de plataformas digitais, a valorização do papel do professor e a importância do desenvolvimento de competências sociais e emocionais" (Magalhães, 2020). Já no que respeita ao CME de Nova Iguaçu, com o isolamento social, por conta da pandemia do COVID-19, o membros tiveram reuniões 
ordinárias e extraordinárias por meio de videoconferência (plataforma Zoom) e "adotou medidas emergenciais, buscando estabelecer diretrizes, orientações e recomendações, seja para o período durante a pandemia como para o retorno das atividades presenciais, no intuito de contribuir com o sistema educacional da rede de ensino (...) tratou-se das questões referentes a alimentação dos educandos (...) e sobre as atividades domiciliares chamadas "atividades remotas", ou "educação remota" (Coelho, 2020).

O tema educação aparece ainda muito associado às modalidades, sobretudo na associação a "distância" (palavra que ocorre 32 vezes), mas trataremos desse subtema em Ensino pois é aí que a associação é mais relevante.

A Educação para a Saúde, tema tratado apenas num texto (no 7), torna-se relevante abordar aqui pois a pesquisadora apresenta dados de um estudo com estudantes do ensino superior em Portugal tendo registado "que os estudantes do Ensino Superior têm baixos conhecimentos de saúde e uma predisposição negativa para terem comportamentos protetores, sendo estas variáveis prenunciadoras de comportamentos de risco para a saúde" (Alves, 2020) e, ao abordar a prevenção da COVID-19, registou que os estudantes têm bons conhecimentos acerca desta doença, mas uma moderada percepção de risco, considerando, pelos comportamentos autorrelatados, que são uma população "em risco de contrair o novo coronavírus" (Alves, 2020).

\subsection{Ensino}

A palavra Ensino é a que per si, sem qualquer palavra adjacente, tem mais ocorrência nos textos das entrevistas (freq. 112). Este tema remete sobretudo para as modalidades, como "presencial", "não-presencial", "a distância", "remoto", "híbrido". Um extrato do texto entrevista no 9 dá o mote para a discussão em volta deste tema com a referência a um conjunto de vocábulos e expressões com que os atores educativos passaram a viver, em todos os níveis de ensino escolar, desde o pré-escolar ao ensino superior:

O momento singular que as escolas e os atores educativos têm vivido no contexto da pandemia introduziu, ao nível dos discursos, um conjunto de vocábulos e expressões, como "aula síncrona", "aula assíncrona", "videoconferência", "plataforma digital", "ensino à distância" e o recurso, ao nível das práticas, a um conjunto de ferramentas digitais, aos quais todos se procuraram adaptar a um ritmo absolutamente inesperado... e necessário (Lamela, 2020).

Uma dessas expressões foi "ensino a distância", usada em textos oficiais (dos ministérios de educação) e na comunicação social, o que levou alguma polêmica sobre o seu uso, pois, dizia-se, que não se estava a fazer "ensino a distância", mesmo no contexto de uma contingência, mas sim "ensino remoto", um termo novo trazido pelo momento singular da pandemia. O texto entrevista no 10, intitulado "Modalidade de Educação a Distância (EaD) versus Ensino Remoto (ER)" (Aguiar, 2020), procura elucidar e distinguir as duas modalidades, entendendo a pesquisadora que "neste momento de demandas educacionais urgentes, não configura EaD e sim o designado "Ensino Remoto". Quais as razões que invoca? Entende que a EaD deve ser pensada como um modalidade educacional "nas suas especificidades próprias, como princípios, concepções, metodologias, 
processo avaliativo e ambiente virtual de aprendizagem devidamente planejado e em rede". Ou seja, continua,

Não podemos entender a EaD somente como um formato educacional que se utiliza de recursos digitais onde a metodologia da modalidade presencial pode ser empregada. Isso é usá-la de forma indiscriminada, sem conhecê-la, ou sequer saber identificar o uso das ferramentas tecnológicas como recurso didático (Aguiar, 2020).

Assim, considera que a expressão "Ensino Remoto" carateriza a medida emergencial no campo da educação, a qual teve

o mérito dos profissionais da educação terem-se empenhado em fazer o seu melhor, com as ferramentas e dispositivos tecnológicos que lhes pareceram viáveis utilizar, mas não possui princípios educacionais que o designe como modalidade educacional enriquecida de pedagogia própria para o processo ensino e aprendizagem (Aguiar, 2020).

É neste tema que alguns pesquisadores falam das condições para implementar os planos de ensino a distância nos respetivos países, em especial em textos entrevistas sobre Angola, Cabo Verde e Moçambique. Sobre Angola, o tema é abordado nos textos entrevistas nos 13 e 21, intitulados "As Condições Tecnológicas e de Ensino a Distância no Ensino Geral e Superior em Angola" (Teixeira, 2020), e "De Angola, reflexões sobre o Ensino a Distância, antes e durante a pandemia" (Lucamba, 2020). Sobre Cabo Verde, nos textos entrevistas nos 18 e 22, intitulados "De Cabo Verde, reflexões sobre as transformações no ensino relacionadas ao uso das tecnologias" e "Em Cabo Verde, as tecnologias educativas na mitigação dos efeitos da COVID-19 (Cardoso, 2020). Sobre Moçambique, nos textos ns 17 e 20 intitulados "Os Desafios da Educação a Distância e ELearning no suporte da Educação Domiciliar em Moçambique em tempos de pandemia" (Tumbo, 2020) e "De Moçambique/África, reflexões sobre os constrangimentos do ensino remoto" (Milicinho, 2020).

De uma forma geral, os pesquisadores relatam o processo, usando diversas tecnologias desde o ensino por correspondência, a meios de comunicação de massa como o rádio e a televisão até às plataformas virtuais online, quando para tal as infraestruturas tecnológicas o permitissem. Nestes países, a transição da aula presencial para a aula a distância, "inaugurando na história o conceito da Ensino Remoto (ER) marcada pela disruptiva migração do Ensino Presencial para o Ensino a Distância (EaD) (Tumbo, 2020), está a ser feita com base, sobretudo, "na 1a geração do Ensino a Distância (correio manual) e 2a geração do Ensino a Distância (rádio e televisão, apesar de também se utilizarem meios tecnológicos de informação e comunicação digitais, responsivos ou instantâneos (Teixeira, 2020). A novidade foi absoluta, pois como relata um jovem pesquisador angolano, pela primeira vez, muitos professores e alunos, vivenciaram algo de novo: "As pessoas da minha geração presenciaram, no país, pela primeira vez, a transmissão das aulas via Televisão Pública de Angola para o ensino primário, e via Rádio Nacional de Angola para o ensino secundário" (Teixeira, 2020). 
É também neste tema que se fala do futuro, no tempo pós-pandemia, sobretudo no texto entrevista no 14, intitulado “Ensino híbrido: será o novo normal da educação?" (Santos, 2020). Remetendo para exemplos de diversos países que já procederam à reabertura das escolas, a jovem pesquisadora considera que "há um consenso que o retorno seja feito de forma gradual e em etapas, mas ainda com o apoio das tecnologias e assim o ensino híbrido surge como uma possibilidade". Prosseguindo na análise, entende que este tipo de ensino, também designado $b$ learning (do termo inglês blended learning), "promove uma mistura entre o ensino presencial e o ensino online, ou seja, uma fusão entre o mundo digital e o físico" e que poderá ser "o legado da pandemia para a educação por ter possibilitado para muitos o primeiro contato com o digital", alertando que "caberá ao coletivo de professores construir esse novo normal, pois o ensino híbrido é muito mais que unir aulas presenciais e a distância. É uma abordagem de ensino baseada na interação e participação ativa de todos".

\subsection{Aprendizagem}

O tema da aprendizagem, para além da sua relação umbilical a ensino, com referência a ambientes virtuais de ensino e aprendizagem, remete sobretudo para as metodologias pedagógicas e para a avaliação. Nas metodologias, destaque para o texto entrevista $n$ o 6 sobre a cultura maker (Aleixo, 2020) que remete para atividades "mão na massa" que "podem ser desenvolvidas em plataformas virtuais ou em espaços físicos", e é baseada em princípios como "o pensamento crítico, protagonismo, autonomia, resolução de problemas, ideias sustentáveis, acessibilidade, dentre outros, aplicados ao fazer", (idem) levando em conta o pensamento de John Dewey, um dos mais reputados educadores do século XX (1859-1952), para quem "a aprendizagem vem da experiência, do "fazer", e a sala de aula deve promover uma reconstrução permanente das vivências de cada aluno, para que eles possa construir o próprio conhecimento" (idem). Destaque também para o texto entrevista $\mathrm{n}-12$, onde a pesquisadora traz elementos da metodologia ativa por meio da Aprendizagem Baseada em Projetos (PBL) combinada com elementos da Gamificação (Araújo, 2020). No seu texto, fala do jogo que criou, denominado BP Game, Business Partners Game, e que foi integrado ao ambiente virtual de aprendizagem Moodle. Ao combinar os princípios da PBL com a Gamificação, a pesquisadora pretende "que os estudantes adquiram conhecimento a partir de um processo que combina a resolução de problemas por meio do trabalho com projetos", ou seja,

o estudante precisa se esforçar para explorar as soluções possíveis dentro de um contexto específico, seja utilizando a tecnologia ou os diversos recursos disponíveis, o que incentiva a capacidade de desenvolver um perfil investigativo e crítico perante alguma situação (Araújo, 2020).

Esta pesquisadora, no seu texto entrevista, olha para o que está a suceder à educação mundial, neste tempo pandêmico, como se estivéssemos a viver "em fases dentro de um caminho desconhecido por muitos "jogadores" (pais, professores, estudantes, reitores, gestores, diretores e encarregados de educação)", narrativa metafórica que reforça "a ideia de que vida e jogo são palavras que se entrelaçam", e entendendo que, como jogadores, "somos indivíduos altamente esperançosos" afirma que ecoa em seus ouvidos a voz maravilhosa de Elis Regina quando canta: 
"Vivendo e aprendendo a jogar, nem sempre ganhando, nem sempre perdendo, mas aprendendo a jogar" (idem, 2020).

No que respeita ao subtema avaliação, o destaque vai para os vários obstáculos em efetuar a avaliação das aprendizagens dos alunos devido aos constrangimentos do ensino remoto. A pesquisadora moçambicana Milicinho (2020) é clara no seu texto entrevista ( $n$ o 20) a este propósito quando afirma que "houve muitos obstáculos para a aprendizagem pois muitos estudantes não possuem telemóveis, tablet e, pior ainda, não têm acesso a internet". Refere que na sua escola, onde leciona, "apenas vinte por cento $(20 \%)$ dos alunos retornam com seu feedback", ficando "difícil de entender se o aluno está a se dedicar ao estudo em casa", considera que, em muitas situações, se está "perante um processo de aprendizagem "muda" (silenciosa) pois não há qualquer retorno de muitos estudantes" (idem).

Daí que o exemplo do Equador, no texto entrevista № 15, intitulado "Do Equador, reflexões sobre a Avaliação das Aprendizagens em tempos de pandemia" (Leal, 2020) traga alguma luz sobre a modalidades de avaliação a priorizar em situações com este contexto de ensino remoto. Neste país, o Ministério da Educação promoveu-se "o desenvolvimento e a aplicação de um modelo de avaliação que privilegia as práticas que são identificadas dentro de um processo de Avaliação Formativa". Esse modelo privilegiou quatro princípios: o uso da autoavaliação, como um instrumento que aos alunos permite "medir, conhecer e tomar decisões sobre o que devem aprender, com base em seus próprios resultados"; solicitar aos alunos que "para a coleta de evidências que confirmarão seus conhecimentos, utilizem uma variedade de métodos de avaliação, como portfólios, trabalhos práticos, projetos, relatórios, reflexões pessoais, entre outros"; realização de atividades que desenvolvam o desenvolvimento do pensamento crítico dos alunos, procurando "garantir que seja contínuo" e "seja capaz de gerar, pelos alunos ou com a ajuda de seus professores, aquelas perguntas que lhes permitem contextualizar, aprofundar e dar sentido às aprendizagens"; por fim, o princípio vinculado à gestão pedagógica dos professores, destacando seu papel de "conselheiro que está em constante comunicação" e, com base na informação coletada e mediante a utilização do feedback, "consegue fornecer aos seus alunos atividades que lhes permitam chegar a atingir os objetivos de aprendizagem e, inclusive, melhorá-los" (idem). Perante esta proposta, o pesquisador não deixa de ficar surpreendido ("Quem diria que, com a chegada do COVID-19, as múltiplas propostas que advogam que os sistemas educacionais optem por uma avaliação de aprendizagem que responda e tenha como objetivo promover e gerar uma aprendizagem significativa"), esperando "que as políticas relativas à aplicação da avaliação da aprendizagem em tempos pós-pandemia continuarão a apostar nas práticas avaliativas para a aprendizagem ou práticas avaliativas da aprendizagem" (idem).

\subsection{Professor}

Esta temática está evidenciada em diversos textos entrevistas e os traços principais relacionam-se com os desafios que os professores tiveram que enfrentar e que competências teriam para atuar num ambiente completamente diferente. Logo no texto entrevista $\mathrm{n} 01$, a pesquisadora aborda esse assunto: "Os professores tiveram que migrar da sala presencial a virtual, adequando 
metodologias com apoio das tecnologias digitais" (Leite, 2020), e o texto entrevista no 2, dá continuidade

O professor presente, atento, que alerta para a falta de atenção, para a falta de estudo, que individualiza o ensino, se assim for necessário, passou para o outro lado do ecrã. $\mathrm{O}$ aluno mais carenciado que vai para a escola, pouco ou até muito motivado, deixa de ter acesso à aula como outrora. Ele não tem computador, ou internet rápida e de acesso ilimitado. Ele deixou de ter as mesmas oportunidades dadas aos colegas. Ele voltou a sentir a desigualdade social... E a escola, o que pode fazer? (E. Rodrigues, 2020).

Perante este novo cenário, inédito, interroga-se a jovem pesquisadora: $\mathbf{O}$ que fazer? Parte da resposta a este desafio foi dada no texto entrevista $n$ - 3, intitulado "Nenhum ser humano é uma ilha" (Ribeirinha, 2020), onde a pesquisadora destaca a atualização urgente efetuada pelos professores, num processo de interação entre "universidades e escolas" e com grupos de apoio aos professores criados nas redes sociais:

Neste contexto, a atualização dos docentes tornou-se urgente, o que potenciou a comunicação entre as universidades e as escolas com a disponibilização de percursos formativos que permitissem a adaptação ao digital. A implementação desses percursos fez-se com o suporte de grupos de apoio aos professores, criados nas redes sociais que, através de uma paciente comunicação, não só asseguraram a implementação como impediram a desmotivação. Nunca antes existiu tanto fluxo comunicativo entre docentes com a partilha e divulgação de experiências, de materiais e de aplicações tecnológicas. (idem).

Esta pandemia pôs a descoberto muitas dificuldades, entre as quais os problemas relacionadas com insuficiente formação dos professores a nível das literacias digitais e de práticas com as Tecnologias Digitais de Informação e Comunicação para atuar na educação online (Teixeira, 2020), fazendo-se "necessária uma formação contínua para professores, com ações que superem a lógica de treinamento, constituindo redes de comunicação, formação e aprendizagem" (A. I. Rodrigues, 2020). Daí que interessa também olhar para o futuro, o tempo pós-pandemia, como é feito no texto entrevista $\mathrm{n}$ - 1, intitulada "E a formação do professor, como será na pós-pandemia? Um caso a pensar" (Leite, 2020). A pesquisadora entende que quem poderá responder a esta pergunta deverão ser os próprios professores "que reinventaram a sala de aula com estratégias pedagógicas emergentes, com o desafio de atender estudantes no processo de aprendizagem, com múltiplas particularidades e ritmos de aprendizado diversos" (idem). São eles os mais competentes

Para prospectar formações que valorizem particularidades e singularidades do professor, uma vez que mesmo diante das condições complexas que permearam a sala de aula atípica, foi capaz de tomar decisões, ser autônomo e fortalecer o seu fazer pedagógico na perspectiva de garantir o aprendizado dos estudantes. (idem).

\subsection{Aluno}

O tema aluno, junto com estudante, surge com relevo na generalidade das entrevistas, muito relacionado a dificuldades com encerramento das escolas e transição das atividades para 
ensino/aprendizagem remota. O texto entrevista $\mathrm{n}$ - 2, já aqui referido no tema dos professores, é também, pelos mesmos motivos evocado para os alunos:

Nestes novos tempos, a escola foi transferida para casa, (...), os alunos mais frágeis foram expostos nas suas dificuldades, nos seus limites económicos, na sua débil condição social, muitas vezes mitigada no dia-a-dia escolar onde tudo parecia estar sob controlo. (E. Rodrigues, 2020).

Nos planos de resposta aos efeitos da COVID-19 na educação, e também nas falas dos professores, há a vontade de promover o sucesso de todos seus alunos traduzida na ideia que "nenhum aluno é deixado para trás!" (idem). Daí que nos textos entrevistas sejam referidas as várias formas de chegar até aos alunos, confinados em suas casas, seja através do envio de material / atividades em formato impresso, pelo serviço de correio postal ou de serviços autárquicos de proximidade, entregando esse material em suas casas, seja recorrendo a emissões de aulas por rádio e por televisão, seja através do uso de tecnologias digitais e da internet, envolvendo os mais variados dispositivos desde o correio eletrônico, redes sociais (como grupos no whatsapp ou facebook) e plataformas de e-learning, as mais diversas.

Na temática "aluno", o subtema mais singular, apesar de só estar tratado num texto entrevista, diz respeito às expetactivas quanto ao futuro. Trata-se do texto entrevista $\mathrm{n}-4$, intitulado "Apareceu uma Pandemia no meio de meu sonho de ingressar no Ensino Superior - E agora?" (Castro, 2020), onde a pesquisadora se coloca na pele de um jovem que acabou de entrar no ensino superior e que perante este cenário pandêmico se interroga quanto ao seu futuro. Em primeiro lugar, a pesquisadora aborda os desafios de transição para o ensino superior que, mesmo em situações normais, "é pautada por uma série de desafios multifacetados para jovens, entre eles, às exigências de habilidades e competências para responderem positivamente às novas demandas de ensino/aprendizagem", sendo, por si só, "um momento de vida com alto nível de stress uma vez que implica numa necessidade de ajustes social e emocional ao novo contexto de exigências educacionais". Face à pandemia, as instituições de ensino superior, implementaram suas metodologias de aprendizado virtual, "não considerando, porém, que nem todas as famílias possuem acesso à internet". Situação também agravada devido aos impactos que a pandemia tem tido na economia, no "aumento do número de desempregados, agravamento da desigualdade social e desestruturação de alguns serviços públicos". Daí, o questionamento da pesquisadora: "Em que isso implica em sua saúde mental, motivação e expectativas positivas quanto ao futuro?".

$\mathrm{Na}$ resposta ao seu questionamento, como pesquisadora no campo da Psicologia da Educação, considera que o "primeiro grande impacto emocional é da impotência diante da realidade de isolamento social (...) que além de manter o jovem em casa, retira deste as estratégias alternativas de contato com os conteúdos programáticos" (uma vez que as bibliotecas e os cyber, que acabam sendo um recurso de acesso à internet, estão fechados) sendo outro fator contributivo "os adoecimentos e falecimentos de familiares, conhecidos e amigos". Outra situação "é a ausência de rotinas nos comportamentos e nas estratégias de estudo adquiridos ao longo dos anos letivos e em ambientes pedagógicos" (presenciais), considerando que está comprovado que os estudantes, mesmo os que fazem uso das estratégias de aprendizagem mais autônomas, quando estão 
"distanciados de seu ambiente de ensino e sem acesso a outros recursos pedagógicos", mesmo que apresentam "níveis de resiliência, motivação, estratégia de estudos e interesses", é esperado que "elaborem crenças negativas quanto suas chances no processo seletivo. Ou seja, que sejam nulas ou menores" (idem). Para muitos estudantes, esta condição é "eliciadora de ansiedades e sentimentos de desmotivação", sendo de esperar haja "momentos de fragilidade e temor quanto suas chances do iminente processo seletivo ao Ensino Superior", problema que as instituições de ensino superior não podem descurar, devendo buscar respostas para evitar (ou minimizar, pelo menos) estas situações.

\subsection{Digital}

A temática do digital é também revelada em vários textos entrevistas, muito relacionada a tecnologias digitais pelas quais passou o processo da transição da atividade de ensino/aprendizagem presencial para o ambiente online, onde "a conceção de recursos multimodais (escritos, áudio e imagem) representou, por esta via, uma prioridade quando sabemos que cada vez mais se aprende e se socializa por intermediação digital" (Faria, 2020).

O processo de digitalização está em curso em diversas atividades da sociedade, como é referido no texto entrevista $\mathrm{n}$ - 5:

Não podemos negar que a aplicação das tecnologias digitais e da internet nos últimos meses vem sendo aplicada exponencialmente em todas as nossas atividades - trabalho, educação, saúde, política e até lazer. Com o digital, e suas potencialidades de interações, informação e comunicação, muitos de nossos afazeres e atividades em fase de isolamento social migraram para o ciberespaço. (Moura, 2020).

Esta jovem pesquisadora aborda a importância que as tecnologias digitais têm para alguns povos indígenas do Brasil, tendo-se realizado, em finais de 2010, na Universidade de São Paulo, o 10 simpósio indígena sobre usos da Internet, que reuniu 24 representantes de comunidades indígenas, oriundos de 16 povos e 13 estados do Brasil. Em seu texto considera que as comunidades indígenas buscaram e se apropriaram das tecnologias digitais tendo "como objetivo principal utilizálas para contribuir no fortalecimento de suas culturas e tradições, e melhorar as condições de vida, sem que percam suas identidades e modos próprios de ser e de viver".

A digitalização, então, como é salientado por Ribeirinha (2020), "está a permitir a sobrevivência de diferentes estruturas económicas e sociais e uma dessas estruturas é a escola", considerando ainda que "mais do que permitir a sua sobrevivência está a operar nela uma mudança há muito esperada, com o desenvolvimento do verdadeiro sentido de comunidade assente nas tão desejadas práticas colaborativas".

Associado ao digital aparece o subtema da literacia digital, na preparação (ou falta dela) dos professores em saberem usar as tecnologias para renovar as práticas pedagógicas, ou seja, como refere o pesquisador moçambicano Dionísio Tumbo, na "divisão digital secundária (referente à literacia digital necessária para operar com e no digital através dos artefactos da cultura digital)" (Tumbo, 2020), aspecto já aflorado na temática "professor". 
Outro subtema é o da inclusão/exclusão digital, muito manifestado nas desigualdades que esta transição para uma "escola digital" veio pôr a descoberto, aspeto que, pela sua importância, se aborda como tema "social" no ponto a seguir.

\subsection{Social}

Com a transição da aula presencial para a aula a distância (online), uma série de dispositivos legais, em cada um dos países, foram criados para que se procedesse com a inclusão social nessa modalidade, em que nenhum aluno fosse deixado para trás. Já afloramos essas disposições em alguns dos temas abordados. No entanto, tal desiderato esteve longe de acontecer, como relevam alguns pesquisadores, em seus textos entrevistas. Falam, assim, das desigualdades sociais sobretudo sentidas pelos alunos oriundos de famílias economicamente mais débeis que foram "expostos nas suas dificuldades", como sinaliza o texto entrevista no 2: "Ele não tem computador, ou internet rápida e de acesso ilimitado. Ele deixou de ter as mesmas oportunidades dadas aos colegas. Ele voltou a sentir a desigualdade social..." (E. Rodrigues, 2020).

Falando de desigualdade social, alguns textos abordam a exclusão digital pelo peso que o fator renda econômica tem nesta problemática, como é salientado no texto entrevista $\mathrm{n}$ ㅇ 23, "sem renda não é possível comprar computador ou pagar um plano de internet" (Braga, 2020).

A importância do acesso à Internet, nesta sociedade digital em que se vive, é reconhecida por diversas instâncias internacionais, nomeadamente pela Organização das Nações Unidas (ONU), entidade que acrescentou esse direito na Carta dos Direitos Humanos, pela resolução A/HRC/32/L.20 aprovada em 10 de julho de 2016, como afirma a jovem pesquisadora no seu texto entrevista (Braga, 2020). Porém, apesar dos esforços que os governos têm feito nos últimos anos, os dados estatísticos disponíveis mostram que ainda há um longo caminho a percorrer. Referindose ao Brasil, e usando os dados do Internet World Stats, referentes a dezembro de 2017, a pesquisadora refere que "apenas $70,7 \%$ da população brasileira faz uso de internet ou seja, 30\% população está excluída digitalmente, cerca de 62 milhões de brasileiros. É muita gente que está excluída desta rede de comunicações" (idem). Mais ainda, salienta que existem fortes assimetrias no país e por isso "inúmeras localidades não foram ainda inseridas no mundo digital", sobretudo no estado do Amazonas onde apenas $46 \%$ da população com acesso à Internet, ou seja, "nesta região mais de metade da população sofre de exclusão digital" (idem).

Idêntico cenário de exclusão digital é trazido por pesquisadores de Moçambique e de Angola. De Moçambique, Tumbo (2020) refere que o índice de penetração da Internet (dados do Censo populacional de 2017) revela que apenas $6,6 \%$ dos habitantes são usuários da rede de internet. Este fato ajuda a compreender a conclusão de Milicinho (2020), também jovem pesquisadora moçambicana, ao dizer que as alternativas encontradas durante o estado de emergência (como a transferências das aulas e outras atividades pedagógicas para plataformas digitais, aulas pela televisão, envio de brochuras digitais aos alunos usando a redes social WhatsApp), "não são inclusivas pois deixam de fora, na sua maior parte, os estudantes que vivem nas zonas rurais". De 
Angola, Teixeira (2020), usando informações da mídia do país, refere que a pandemia trouxe à tona diversos problemas, relacionados a escolas, professores e alunos. No que respeita aos alunos, sinaliza "os problemas ligados à falta de um computador ou um smartphone na família, a falta de recursos para acesso a internet em casa, e a falta de literacia digital" e, segundo opinião de alguns alunos que tinham os meios tecnológicos, o problema persiste pois a "região ou localidade onde vivem não tem cobertura da internet e luz eléctrica, impedindo-os de participar na aula online assíncrona".

O que esta temática nos traz, sobretudo, é que há necessidade de reforçar as condições de acesso às tecnologias e à rede internet para que a transição para o digital, ou convivência com esse mundo, seja feito num quadro de igualdades de oportunidades, caso contrário há um agravamento das desigualdades sociais. Pensando no tempo pós-pandemia, como é feito no texto no14 ao referirse que o "ensino híbrido poderá ser será o novo normal da educação" (Santos, 2020), é avisado o alerta dos especialistas, como mencionado pela pesquisadora, que esse cenário requer a "construção de um planejamento adequado a cada realidade sob o risco de que este novo normal não agrave ainda mais as desigualdades existentes".

\subsection{Escola}

Propositadamente, terminamos esta análise temática com o tema sobre a Escola, pois foi aqui que tudo começou, com medidas de isolamento, em meados do mês de março de 2020 (nos diversos países), e todos desejam que se proceda à sua reabertura, mesmo no contexto de termos de aprender com a COVID-19, até que, por inovação da ciência, seja criada uma vacina ou medicamento eficaz para livrar a humanidade deste pesadelo.

O tema "escola" aparece articulado com seu "encerramento", tendo sido "transferida para casa" (E. Rodrigues, 2020), "para o espaço da casa de cada um" (Lamela, 2020). Trata-se de um fato inédito na história da humanidade, pelo menos desde a era moderna quando a escola adquiriu caráter de frequência universal (escola para todos) e obrigatória nos níveis de escolaridade básica e, em alguns países, mesmo no nível de ensino médio (também chamado de secundário). Deste modo, pela primeira vez na história milhões de crianças e jovens não puderam frequentar a escola, de ensino-aprendizagem presencial (tal como a conhecemos), tendo as atividades letivas sido desenvolvidas numa determinada modalidade a distância, em que uma "inesperada rede colaborativa tornou possível a criação de uma escola digital, que, não sendo a ideal, foi a possível" (Ribeirinha, 2020), de acordo com as condições de cada país. Estes aspectos já foram abordados em outros temas, no decurso desta análise. Interessa, assim, buscar uma outra abordagem que é tratada em alguns textos, no sentido de fazer desta experiência uma oportunidade de renovação desta instituição multisecular, pois a sua origem remonta ao tempo da invenção da escrita, por volta do século IV a.C. (Silva, 2008).

Esse assunto é tratado, sobretudo, nos textos entrevistas nos 2 e 9 que abordam a avaliação das escolas. Assim, E. Rodrigues (2020) refere que o novo ciclo de avaliação externa das escolas, em Portugal, "enaltece práticas de inclusão, favorece as escolas inovadoras e flexíveis, aplaude as escolas que promovem o sucesso de todos os seus alunos - onde nenhum aluno é deixado para trás" 
(idem), e considera que é "aqui que as escolas se poderão destacar: no modo como conseguiram, ou não, incluir todos os seus alunos, como envolveram a comunidade para reduzir as desigualdades econômicas e sociais, o seu contributo na irradicação da pobreza aliado a uma educação de qualidade" (idem). Dessa avaliação, em que todos os atores educativos serão chamados a se pronunciarem sobre a forma como ultrapassaram esta ameaça pandêmica, a pesquisadora tem a esperança que todos "sairemos mesmo mais fortes, mais alertas, mais sensíveis e mais humanos deste ano 2020" (idem).

Na mesma linha de pensamento, também Lamela (2020) considera que o processo de autoavaliação da escola tem um "papel preponderante para a melhoria do serviço educativo prestado", e que a organização escolar

com a participação direta dos vários atores educativos (...) não desperdiçará, seguramente, este momento peculiar para envolver os principais interlocutores do processo educativo (...) na redefinição de estratégias, na reorganização de processos e na reformulação de práticas que incorporem um vasto conjunto de ferramentas e recursos tecnológicos no contexto da sala de aula ou fora da mesma.

Ainda neste sentido, mas focando no processo de digitalização em curso, entende a pesquisadora Ribeirinha (2020), que a digitalização, mais do que permitir a sobrevivência da escola ("escola digital") "está a operar nela uma mudança há muito esperada, com o desenvolvimento do verdadeiro sentido de comunidade assente nas tão desejadas práticas colaborativas" (idem). Aleixo (2020), também reforça a necessidade de "reinventar a escola, seus espaços, suas rotinas, formas de ensinar para que novos ambientes de livre autoria e expressividade sejam criados", e que no "contexto de transformações desejáveis, os espaços Maker têm o potencial de reinventar o contexto escolar e ser um propagador da cultura de inovação na escola" (idem).

Destacamos, em tema anterior, o fator das desigualdades sociais e digitais, e pode-se questionar, como faz a jovem pesquisadora Wylnara Braga, em seu texto entrevista (Braga, 2020): Que pode a escola contra a exclusão social? Recorrendo a pesquisa de Sarmento (2002), apesar de entender que a escola não pode modificar essa realidade por completo, visto que a "exclusão social é fruto das desigualdades sociais presentes na sociedade capitalista", ela "pode ser um local de transformação social e institucional. A escola é um agente transformador e, por isso, a educação tem esse condão de garantia e de luta pelos direitos sociais" (idem). E a escola tem também "uma agência na luta pela inclusão digital", pois, recorrendo as pesquisas efetuadas por Silva e Pereira (2008), pensamos que é na escola que muitas crianças e jovens, sobretudo as que vivem em meios mais desfavorecidos, contactam pela primeira vez com as tecnologias digitais e é também aí que aprendem a fazer um uso consciente, crítico e criativo das tecnologias.

\section{CONSIDERAÇÕES FINAIS}

As constatações da presente pesquisa, baseada na exploração das vinte e três entrevistas de jovens pesquisadores, todos com raízes no doutoramento em Ciências da Educação da Universidade do Minho em Portugal, mas oriundos (ou residentes de momento) de sete países localizados em 
quatro continentes, que a experiência educativa vivida provocada pelo coronavírus teve contornos muitos semelhantes em cada um dos países, com o isolamento social (desde março de 2020) das escolas e transição das atividades letivas para ambientes a distância, optando-se, em cada país, pelas formas e meios possíveis, de acordo com as condições das infraestruturas tecnológicas existentes.

Os textos entrevistas revelam as especificidades dos projetos de pesquisa, os quais respondem a muitas inquietações, desde questões de políticas educativas, do ensino e da aprendizagem, do papel dos professores e do alunos, do potencial das tecnologias digitais, das desigualdades sociais e exclusão digital, da ameaça à escola mas também da oportunidade que este momento pode representar para a sua renovação e, aqui, o papel preponderante que a autoavaliação da escola pode ter para melhorar o serviço educativo prestado. Essas inquietações representam inúmeros desafios que foram (e são) colocados a instâncias de decisão nas políticas educativas, a instituições, professores, alunos, famílias, entre outros atores com influência na educação escolar. As narrativas dos textos são plurais, enumeram muito desses desafios e também apontam caminhos possíveis para melhorar o serviço educativo, seja em tempos ainda de pandemia seja para os tempos pós-pandemia.

A pandemia tem mostrado a extraordinária utilidade da Internet em todos os âmbitos, como foi o caso deste Projeto de Extensão, pois, estando os jovens pesquisadores isolados em suas casas, com suas tecnologias digitais e Internet foi possível elaborar e partilhar suas narrativas, num movimento de trabalho integrador (entre instâncias do IFRN e da UMinho) veiculado para o ciberespaço pelo portal online do Jornal Potiguar Notícias, fazendo com que seus textos chegassem a milhares de pessoas a partir de entrevistas. Como exterioriza a jovem pesquisadora Teresa Ribeirinha "se a pandemia nos isolou nas nossas próprias ilhas, as tecnologias digitais estão a combater a insularidade garantindo o vital suporte social através de uma das suas principais funções: a comunicação em rede" (Ribeirinha, 2020).

Este período que estamos a viver não foi (e não é ainda) um momento fácil, para todos, instituições e pessoas envolvidas na educação, em geral, mas sobretudo na educação escolar. A esperança é que a Ciência encontre a solução "milagrosa", rapidamente, por meio de uma vacina ou medicação eficazes, e que no período pós-pandemia, alavancados por esta experiência de Ensino Remoto, possamos construir inovações para o futuro. A Educação/Ensino presencial nunca desaparecerá, faz parte do ADN da Humanidade, mas é possível renovar e inovar nessa instituição secular, talvez caminhando para um sistema híbrido (como exterioriza a jovem pesquisadora Luciana Santos), em que o presencial e o online se complementem, caminho esse que está em correspondência aos tempos da sociedade digital que vivemos, de uma cibercultura avançada móvel e ubíqua.

\section{REFERÊNCIAS}

Aguiar, G. P. DE. (2020). Modalidade de Educação a Distância (EaD) versus Ensino Remoto (ER). [Entrevista concedida a Tavares, A., \& Silva, B]. Jornal Potiguar Notícias. (Texto entrevista no 10) 
Recuperado de: https://www.potiguarnoticias.com.br/noticias/46078/modalidade-deeducacao-a-distancia-ead-versus-ensino-remoto-er.

Aleixo, A. (2020). Makers Mudam o Mundo e Reinventam a Escola. [Entrevista concedida a Tavares, A., \& Silva, B]. Jornal Potiguar Notícias. (Texto entrevista no 6). Recuperado de: https://www.potiguarnoticias.com.br/noticias/45936/makers-mudam-o-mundo-ereinventam-a-escola.

Alves, R. (2020). Educação para a Saúde no Ensino Superior: Health On You Program. [Entrevista concedida a Tavares, A., \& Silva, B]. Jornal Potiguar Notícias. (Texto entrevista no 7). Recuperado de: https://www.potiguarnoticias.com.br/noticias/45984/de-portugal-a-pesquisadora-reginaalves-fala-sobre-ensino-superior-e-saude.

Araújo, A. (2020). Estamos Dentro de um Grande Jogo: Vivendo e Aprendendo a Jogar. [Entrevista concedida a Tavares, A., \& Silva, B]. Jornal Potiguar Notícias. (Texto entrevista no 13). Recuperado de: https://www.potiguarnoticias.com.br/noticias/46180/estamos-dentro-de-um-grandejogo-vivendo-e-aprendendo-a-jogar.

Bourdieu, P. (1989). O poder simbólico. Rio de Janeiro: Editora Bertrand.

Braga, W. (2020). De Manaus/Brasil, a pandemia reforçou a necessidade de se promover a inclusão digital. [Entrevista concedida a Tavares, A., \& Silva, B]. Jornal Potiguar Notícias. (Texto entrevista no 23). Recuperado de: https://www.potiguarnoticias.com.br/noticias/46335/demanausbrasil-reflexoes-sobre-o-valor-da-inclusao-digital-com-a-pandemia.

Braun, V., \& Clarke, V. (2013). Successful qualitative research: A practical guide for beginners. Los Angeles/London/New Delhi/Singapore/Washington, DC: SAGE Publications.

Braun, V., \& Clarke, V. (2006). Using thematic analysis in psychology. Qualitative Research in Psychology, 3(2), 77-101. https://doi.org/10.1191/1478088706qp063oa.

Castro, A. C. R. DE. (2020). Apareceu uma Pandemia no meio de meu sonho de ingressar no Ensino Superior- E agora?. [Entrevista concedida a Tavares, A., \& Silva, B]. Jornal Potiguar Notícias. (Texto entrevista no 4 ). Recuperado de: https://www.potiguarnoticias.com.br/noticias/45842/pandemia-no-meio-de-meu-sonho-deingressar-no-ensino-superior-e-agora.

Cardoso, S. (2020). Em Cabo Verde, as tecnologias educativas na mitigação dos efeitos da COVID19. [Entrevista concedida a Tavares, A., \& Silva, B]. Jornal Potiguar Notícias. (Texto entrevista no 22). Recuperado de: https://www.potiguarnoticias.com.br/noticias/46316/em-cabo-verdeas-tecnologias-educativas-na-mitigacao-dos-efeitos-da-covid-19.

Coelho, A. A. (2020). Contributos dos Conselhos Municipais de Educação em tempos de Pandemia. [Entrevista concedida a Tavares, A., \& Silva, B]. Jornal Potiguar Notícias. (Texto entrevista no 11). Recuperado de: https://www.potiguarnoticias.com.br/noticias/46128/contributos-dosconselhos-municipais-de-educacao-em-tempos-de-pandemia. 
FARIA, P. M. (2020). De Timor Leste, plano de ação concebido para o período de suspensão das atividades académicas motivado pela pandemia COVID-19. [Entrevista concedida a Tavares, A., \& Silva, B]. Jornal Potiguar Notícias. (Texto entrevista no 19). Recuperado de: https://www.potiguarnoticias.com.br/noticias/46268/de-timor-leste-asia-plano-de-acaoacademico-para-o-periodo-pandemico.

Freire, P. (2005). Pedagogia da Autonomia. Rio de Janeiro: Paz e Terra.

Lamela, C. (2020). Autoavaliação em tempos de pandemia: dar voz aos que reinventaram os modos de ensinar e de aprender. [Entrevista concedida a Tavares, A., \& Silva, B]. Jornal Potiguar Notícias. (Texto entrevista no 9). Recuperado de: https://www.potiguarnoticias.com.br/noticias/46057/de-portugal-entrevista-com-conceicaolamela-sobre-autoavaliacao-na-pos-pandemia.

Leal, J. (2020). Do Equador, reflexões sobre a Avaliação das Aprendizagens em tempos de pandemia. [Entrevista concedida a Tavares, A., \& Silva, B]. Jornal Potiguar Notícias. (Texto entrevista no 15). Recuperado de: https://www.potiguarnoticias.com.br/noticias/46197/do-equadorreflexoes-sobre-a-avaliacao-das-aprendizagens-em-tempos-de-pandemia.

Leite, E. A. M. (2020). A formação de professores no período pós-pandemia. [Entrevista concedida a Tavares, A., \& Silva, B]. Jornal Potiguar Notícias. (Texto entrevista no 1). Recuperado de: https://www.potiguarnoticias.com.br/noticias/45736/entrevista-com-a-pesquisadora-elianaleite-sobre-formacao-docencia-e-pandemia.

Lucamba, A. (2020). De Angola, reflexões sobre o Ensino a Distância, antes e durante a pandemia. [Entrevista concedida a Tavares, A., \& Silva, B]. Jornal Potiguar Notícias. (Texto entrevista № 21). Recuperado de: https://www.potiguarnoticias.com.br/noticias/46303/de-angola-reflexoessobre-o-ensino-a-distancia-antes-e-durante-a-pandemia.

Magalhães, P. (2020) Escola e a Educação Urbana: do Projeto Educativo à construção de Comunidades de Aprendizagem. [Entrevista concedida a Tavares, A., \& Silva, B]. Jornal Potiguar Notícias. (Texto entrevista no 16). Recuperado de: https://www.potiguarnoticias.com.br/noticias/46220/de-portugal-entrevista-de-patriciamagalhaes-sobre-escola-e-educacao-urbana.

Milicinho, A. (2020). De Moçambique/África, reflexões sobre os constrangimentos do ensino remoto. [Entrevista concedida a Tavares, A., \& Silva, B]. Jornal Potiguar Notícias. (Texto entrevista no 20). Recuperado de: https://www.potiguarnoticias.com.br/noticias/46283/emmocambique-africa-educacao-escolar-durante-o-estado-de-emergencia.

Moura, S. (2020) Povos Indígenas, Tecnologias Digitais e Educação. . [Entrevista concedida a Tavares, A., \& Silva, B]. Jornal Potiguar Notícias. (Texto entrevista no 5). Recuperado de: https://www.potiguarnoticias.com.br/noticias/45904/povos-indigenas-tecnologias-digitais-eeducacao.

Nogueira, L. S. (2020). De Cabo Verde, reflexões sobre as transformações no ensino relacionadas ao uso das tecnologias. [Entrevista concedida a Tavares, A., \& Silva, B]. Jornal Potiguar Notícias. 
(Texto entrevista no 18). Recuperado de: https://www.potiguarnoticias.com.br/noticias/46264/de-cabo-verde-reflexoes-sobre-astransformacoes-no-ensino-e-o-uso-de-tecnologia.

Ribeirinha, T. (2020). Nenhum ser humano é uma ilha. [Entrevista concedida a Tavares, A., \& Silva, B]. Jornal Potiguar Notícias. (Texto entrevista no 3). Recuperado de: https://www.potiguarnoticias.com.br/noticias/45819/entrevista-com-teresa-ribeirinhanenhum-ser-humano-e-uma-ilha.

Rodrigues, A. I. (2020). Multi Tecnologias Digitais de Informação e Comunicação para enfrentar os tempos pandémicos. [Entrevista concedida a Tavares, A., \& Silva, B]. Jornal Potiguar Notícias. (Texto entrevista $\mathrm{n}$ - 8) Recuperado de: https://www.potiguarnoticias.com.br/noticias/46014/multi-tecnologias-digitais-deinformacao-e-comunicacao-e-a-docencia-online

Rodrigues, E. (2020). Docência e Aprendizagem em 2020. [Entrevista concedida a Tavares, A., \& Silva, B]. Jornal Potiguar Notícias. (Texto entrevista $\mathrm{n}-2$ 2). Recuperado de: https://www.potiguarnoticias.com.br/noticias/45771/entrevista-com-a-pesquisadoraportuguesa-eduarda-rodrigues-sobre-educacao.

Santos, L. (2020) PANDEMIA: contexto de transformação de comportamento. [Entrevista concedida a Tavares, A]. Jornal Potiguar Notícias. Recuperado de: https://www.potiguarnoticias.com.br/colunas/post/3215/pandemia-contextodetransformacao-de-comportamento.

Santos, L. (2020). Ensino híbrido: será o novo normal da educação? . [Entrevista concedida a Tavares, A., \& Silva, B]. Jornal Potiguar Notícias. (Texto entrevista no 14). Recuperado de: https://www.potiguarnoticias.com.br/noticias/46172/ensino-hibrido-sera-o-novo-normal-daeducacao.

Sarmento, M. J. (2002) Infância, exclusão social e educação como utopia realizável. Educação \& Sociedade. 23(78), 265-283. https://doi.org/10.1590/S0101-73302002000200015.

Silva, B. (2008). Tecnologias, Ecologias da Comunicação e Contextos Educacionais. In Martins, Moisés \& Pinto, M. (Orgs.). Comunicação e Cidadania - Actas 5o Congresso da Associação Portuguesa de Ciências da Comunicação. Braga: Centro de Estudos de Comunicação e Sociedade (Universidade do Minho), pp. 1908-1920. (ISBN 978-989-95500-1-8).

Silva, B., \& Pereira M. G. (2011). Contributos da Escola para a Inclusão Digital. Innovación Educativa, no 21, número temático "Educación Inclusiva". Vigo: IEC - Instituto de Ciencias da Educación da Universidade de Santiago de Compostela, pp. 217-227. Recupeerado de: https://revistas.usc.gal/index.php/ie/article/view/35.

Strauss, A., \& Corbin, J. (1990) Basics of qualitative research: Grounded theory procedures and techniques. Thousand Oaks, CA: Sage Publications, Inc. 
Teixeira, M. (2020). As condições Tecnológicas e de Ensino a Distância no Ensino Geral e Superior em Angola. [Entrevista concedida a Tavares, A., \& Silva, B]. Jornal Potiguar Notícias. (Texto entrevista no 12). Recuperado de: https://www.potiguarnoticias.com.br/noticias/46148/deangolaafrica-reflexao-sobre-a-educacao-a-distancia-de-emergencia.

Tumbo, D. (2020). Os Desafios da Educação a Distância e E-Learning no suporte da Educação Domiciliar em Moçambique em tempos de pandemia: um sonho possível. [Entrevista concedida a Tavares, A., \& Silva, B]. Jornal Potiguar Notícias. (Texto entrevista no 17). Recuperado de: https://www.potiguarnoticias.com.br/noticias/46242/desafios-da-educacao-a-distancia-e-elearning-em-mocambique-um-sonho-possivel.

\section{COMO CITAR ESTE ARTIGO:}

TAVARES, A. M. B. do N., SILVA, B. D. da (2020). Reflexão de jovens pesquisadores sobre a experiência educativa diante do contexto pandêmico da COVID-19. Holos. 36(5), 1-26.

\section{SOBRE OS AUTORES}

\section{A. M. B. do N. TAVARES}

Doutora e Mestre em Ciências da Educação pela UFRN e Pós-Doutorada pela Universidade do Minho/Portugal. Possui Curso de Pedagogia, Curso de Jornalismo, Pós-Graduação em Psicopedagogia Clínica e Pós-Graduação em Educação Profissional pelo IFRN. É Professora do Instituto Federal de Educação, Ciência e Tecnologia do Rio Grande do Norte (IFRN) onde realiza atividades de ensino, pesquisa, extensão e internacionalização. Também no IFRN, atua como Professora do Programa de Pós-Graduação Acadêmica (PPGEP/IFRN), do Mestrado Profissional em Ensino de Física (MNPEF/IFRN) e dos Cursos Superiores de Graduação. Atuou como Coordenadora Institucional do Programa PIBID/IFRN financiado pela agência de fomento CAPES, no período de 2013 até 2018. Atualmente, é Coordenadora Institucional do Programa de Residência Pedagógica/IFRN financiado pela agência de fomento CAPES, de 2018 até o ano corrente. No campo das atividades de Extensão, Coordena o Projeto "Diálogos sobre Capital Cultural e Práxis do IFRN", desde 2017. No campo da pesquisa, é membro do Grupo de Pesquisa vinculado ao CNPQ "Escola Contemporânea e Olhar Sociológico (ECOS)" que realiza investigação no campo das ciências da educação junto à linha de pesquisa "Sociologia educacional e ação pedagógica", na UFRN. No Jornalismo, compõe a equipe de redação (escreve, reporta e noticia) do complexo de comunicação "Potiguar Notícias" por meio do jornal eletrônico, da rádio e da TV digital (PNTV). As atividades profissionais realçam proximidade com os objetos de pesquisa: Formação de professores, Educação Profissional, Ensino Superior, Processos Cognitivos e Teorias da Aprendizagem, Educação Escolar e Não-Escolar e Comunicação Social. E-mail: andrezza.tavares@ifrn.edu.br

ORCID ID: https://orcid.org/0000-0001-6857-7947

\section{B. D. da SILVA}

Bento Duarte da Silva - Doutorado em Educação, na área da Tecnologia Educativa e Professor Catedrático do Instituto de Educação da Universidade do Minho (recém aposentado). Foi Vice-Presidente do Instituto de Educação; Diretor do Departamento de Estudos Curriculares e Tecnologia Educativa; Coordenador da área de Especialização de Tecnologia Educativa do Mestrado em Ciências da Educação, e Coordenador da especialidade de Tecnologia Educativa no Doutoramento em Ciências da Educação. Atualmente, é membro do Centro de Competência da UMinho para a área das Tecnologias de Informação e Comunicação na Educação; e é Presidente da Associação Científica Internacional de Psicopedagogia. Desenvolve, ainda, atividades de pesquisa no Centro de Investigação em Educação na UMinho e atividades de orientação nos Programas de Pós-Graduação em Tecnologia Educativa (Mestrado e Doutoramento) no Instituto de Educação 
da UMinho. É autor de cerca de trezentos trabalhos de investigação sobre TIC na Educação. E-mail: bento@ie.uminho.pt

ORCID ID: http://orcid.org/0000-0001-5394-5620

Editor(a) Responsável: Francinaide de Lima Silva Nascimento

Pareceristas Ad Hoc: ADRIANA SOUZA E LENINA SILVA

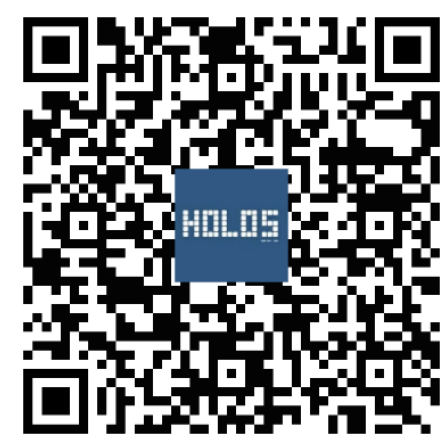

